\title{
ДОБРОСОВЕСТНЫЙ ПРИОБРЕТАТЕЛЬ: ПОНЯТИЕ, ПРАВОВОЕ ПОЛОЖЕНИЕ
}

\section{BONA FIDE ACQUIRER: CONCEPT, LEGAL STATUS}

\section{A. Gudkov \\ A. Krasilschikov \\ V. Mishchenko}

Summary. In this article, the author examines the issue of the concept and legal status of a bona fide purchaser. The emphasis is made on the fact that the current legislation does not have a specific definition as to what a bona fide acquisition is, while the stability of the legal status of a bona fide acquirer is inextricably linked with the perfection of legal mechanisms that determine measures and methods of protecting the property rights of citizens and legal entities in various conditions. The author also provides examples of the implementation of such mechanisms.

Keywords: conscientious acquirer; property rights, legislation, acquisitive prescription, good faith.

$\Pi$ оиск верного определения того, что собой представляет такой феномен гражданско-правовых отношений, как добросовестный приобретатель возможен путем разрешения вопроса о категоричности его основных признаков, которые на сегодняшний день не имеют четкой правовой регламентации.

Как справедливо отмечает Д.А. Кикеева вопрос определения понятия добросовестного приобретателя, а также его статуса в отечественной доктрине, до настоящего времени, окончательно не решен. В значительной мере, этому способствует постоянно меняющиеся отношения в сфере реализации права собственности и иных вещных прав, а также внедрение новых механизмов гражданско-правового оборота, которые, как показывает практика, каждый раз нарушают устойчивое представление ученых и исследователей о его свойствах [6, С. 216].

К примеру, одной из традиционных точек зрения об особенностях рассматриваемого понятия является позиция о том, что основным фактором реального возникновения и действия статуса добросовестного приобретателя является момент передачи спорной вещи

\author{
Гудков Анатолий Иванович \\ К.ю.н., дочент, ВЮИ ФСИН России \\ gudkovaniv@yandex.ru \\ Красильщиков Анатолий Владимирович \\ К.ю.н., дочент, ВЮИ ФСИН России \\ krasilschikov@inbox.ru \\ Мищенко Вячеслав Иванович \\ К.ф.н., дочент, ВЮИ ФСИН России \\ vyacheslav-mischenko@mail.ru
}

Аннотация. В данной статье автором рассматривается вопрос понятия и правового положения добросовестного приобретателя. Делается акцент на том, что действующее законодательство не имеет конкретной дефиниции относительно того, что такое добросовестное приобретение, при этом устойчивость правового статуса добросовестного приобретателя неразрывно связана с совершенством правовых механизмов, которые определяют меры и способы защиты вещных прав граждан и юридических лиц в различных условиях. Также автором приводятся примеры реализации таких механизмов.

Ключевые слова: добросовестный приобретатель; вещное право, законодательство, приобретательная давность, добросовестность.

от одного лица к другому [5, С. 156]. Между тем, противовесом такому подходу служит другая позиция, в соответствии с которой добросовестность в вопросе приобретения конкретной вещи не может быть разрешена только путем её получения, в том числе и в том случае, если такая вещь перешла в собственность другого лица на законном основании. Сторонники указанной позиции полагают, что истинное представление о добросовестном приобретении может формироваться исключительно на основании учета давности нахождения какой-либо вещи в собственности лица, а также давности, которая достаточно точно определяет отсутствие взаимосвязи между лицом и вещью [7, С. 543].

Стоит сразу же отметить, что представленной точкой зрения нивелируется изначально выработанная позиция законодателя в том, что правовое положение добросовестного приобретателя, введенное в действие положениями Гражданского Кодекса Российской Федерации [1] (ст. 302 ГК), имеет отличие от правового положения приобретателя, ставшего таковым вследствие давностного владения (ст. 234 ГК). То есть, как следует из положений ст. 302 ГК РФ, правовой статус добросовестного приобретателя всецело связан с моментом приобретения вещи и, с учетом влияния на данные 
отношения сторонних факторов, остается неизменным до момента её отторжения. В то время как давностное приобретение - это положение приобретателя, зависящее от ряда условий, основными из которых являются: добросовестность, открытость, отношение владельца к вещи как к своей собственной. Здесь же стоит напомнить о том, что состояние добросовестности такого владельца признается законным только в том случае, если владелец вещи неосознанно нарушает право иного лица, при этом не зная об этом в течении всего срока приобретательной давности. Аналогичная позиция может иметь выражение в отношении остальных свойств давностного владения: соблюдение правил приобретательной давности будет признаваться законным только в случае, если их проявление будет соблюдаться на протяжении всего срока.

В свою очередь, механизм защиты вещных прав, предусмотренных ст. 302 ГК РФ, выстроен на понимании того, что вещь перешла владельцу на основании добросовестного приобретения, а не продолжительного добросовестного владения, следовательно, добросовестность, как свойство определения правового статуса владельца вещи непосредственно связана только с одним обстоятельством - моментом её передачи. В таком случае, риск утраты добросовестности, к примеру, если владелец узнал о том, что данная вещь перешла к нему с нарушением прав иного лица, отсутствует, так как с учетом соблюдения известнейшего принципа, действовавшего в римском праве «mala fides superveniens non nocet» правовые последствия, которые могут проявиться в случае незаконного приобретения, в данной ситуации не наступают.

Примером действия указанного принципа является законодательство такой страны, как Франция, где в соответствии со ст. 2268 ГК Франции, добросовестность признается установленной, если в момент совершения сделки относительно спорного имущества, были соблюдены правила её передачи, то есть, были на лицо [3]. Вместе с тем, в законодательстве Германии вышеу-

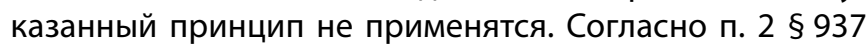
Германского гражданского уложения (BGB) [4] приобретение может быть исключено, если лицо, которое стало обладать вещью впоследствии узнало о том, что он не обладает правом собственности, либо вещь принадлежит иному лицу, и была передана ему без согласия последнего.

Как мы видим, позиции законодательного регулирования вопроса добросовестного приобретения могут быть разнообразными и достаточно гибкими, если для справедливой оценки ситуации необходимо корректировать действующие нормы. Наиболее точным отражением данной точки зрения является недавнее решение Конституционного суда РФ, который, рассматривая вопрос о конституционности положений ст. 302 ГК РФ, постановил внести изменения в указанную норму. Основанием для предпринятых изменений стало несовершенство механизма защиты добросовестного приобретателя в вопросе защиты прав собственности на недвижимое имущество. Причиной к этому послужила история, произошедшая с добросовестным приобретателем из Ангарска. Последний приобрел квартиру, не зная, что продавец не получил разрешения на её отторжение со стороны другого собственника - своей жены. В результате, когда собственница заявила свои требования на спорное имущество, суды встали на её сторону, и обстоятельства, согласно которым, у настоящего владельца были документы, подтверждающие законность и добросовестность заключенной сделки, учитывать не стали, сославшись именно на положения ст. 302 ГК РФ. Конституционный Суд РФ, рассмотрев жалобу добросовестного приобретателя, указал, что дело по иску бывших владельцев подлежит пересмотру, при том, что суды, рассматривающие его, должным образом не учли то, что добросовестный приобретатель при заключении сделки опирался на данные из ЕГРН и стал собственником на законных основаниях [8].

Отдельно стоит обратить внимание на то, что, указывая на необходимость внесения дополнений в ст. 302 ГК РФ, суд де-факто сформировал новый признак приобретательной добросовестности, отнеся к нему такое качество приобретателя как осмотрительное поведение. В частности, Конституционный Суд подчеркнул, что сведения из ЕГРН, в вопросе установления легитимности отторжения и действующего права собственности недвижимого имущества, являются достаточными для того, чтобы полагать, что его приобретение было совершено на добросовестных началах. Иное означало бы, что система государственной регистрации недвижимости нашей страны не обладает достаточной зашитой указанных прав.

Представленная точка зрения показывает, что устойчивость правового положения добросовестного приобретателя неразрывно связана с состоянием и совершенством правовых механизмов, которые определяют меры и способы защиты вещных прав граждан и юридических лиц в различных условиях. Примером реализации такого механизма стали последние законодательные новеллы, согласно которым с 2020 года Федеральным законом № 218-Ф3 «О государственной регистрации недвижимости» [2] установлена денежная компенсация для добросовестных приобретателей, которые утратили свое недвижимое имущество. Основанием для принятия компенсационных мер является решение суда, установившего, что добросовестное приобретение было реализовано в отношении спорно- 
го имущества. В частности, как указано в законе, добросовестный приобретатель, вправе требовать компенсацию за утрату законно приобретенного жилья при условии, если он лишился его по вине недостоверной информации, предоставленной органами регистрации недвижимого имущества.

Таким образом, мы видим, что правовое положение добросовестного приобретателя не имеет законодательного определения и четкой правовой регламентации в гражданском законодательстве. Более того, если коснуться более предметной оценки признаков данного явления, то можно убедиться в том, что оно по своей правой сущности является производным от представления о том, каким образом необходимо осуществлять защиту прав собственника, если действия, направленные им на приобретение вещи, были абсолютно законными. Следовательно, правовое положение добросовестного приобретателя находит свое выражение в применении конкретного механизма защиты вещных прав, внесение изменений в который, безусловно влечет за собой и изменение его статуса.

\section{ЛИТЕРАТУРА}

1. Гражданский кодекс Российской Федерации (часть первая) от 30.11.1994 N51-Ф3 (ред. от 28.06.2021, с изМ. от 08.07.2021) // Собрание законодательства РФ. 05.12.1994. N32. ст. 3301.

2. Федеральный закон от 13.07.2015 N218-Ф3 (ред. от 01.07.2021) «0 государственной регистрации недвижимости» (с изм. и доп., Вступ. в силу с 12.07.2021) // Собрание законодательства РФ. 20.07.2015. N29 (часть І). ст. 4344.

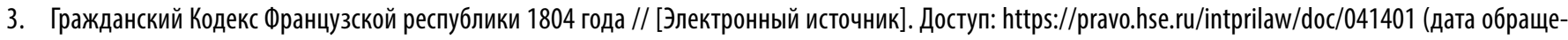
ния: 16.07.21).

4. Bürgerliches Gesetzbuch — BGB / Гражданское Уложение Германии (ГГу) // [Электронный источник]. Доступ: https://www.drjv.org/dgesetze.html (дата обращения: 16.07.21).

5. Загоруйко И.Ю. К вопросу о защите прав добросовестного приобретателя недвижимого имущества. В сборнике: Актуальные вопросы развития гуманитарной и социально-экономической мысли в современных реалиях. Сборник трудов Межвузовской научно-практической конференции с международным участием. Пермь, 2020. С. 156-162.

6. Кикеева Д.А. Правовые аспекты защиты прав добросовестного приобретателя недвижимого имущества. В сборнике: Всероссийская конференция молодых исследователей с международным участием «Социально-гуманитарные проблемы образования и профессиональной самореализации» (Социальный инженер-2020). сборник материалов Всероссийской конференции молодых исследователей с международным участием. Москва, 2020. C. 215-220.

7. Семенюк Р.В. К вопросу о добросовестности приобретателя в гражданско-правовых сделках. Аллея науки. 2020. Т. 1. № 5 (44). С. $540-543$.

8. КС защитил добросовестных приобретателей имущества [Электронный источник]. Доступ: https://realty.rbc.ru/news/60ed80a99a79475899a1e449 (дата обращения: 16.07.21).

(с) Гудков Анатолий Иванович ( gudkovaniv@yandex.ru ),

Красильщиков Анатолий Владимирович ( krasilschikov@inbox.ru ), Мищенко Вячеслав Иванович ( vyacheslav-mischenko@mail.ru ).

Журнал «Современная наука: актуальные проблемы теории и практики» 